\title{
GaP/GaPN core/shell nanowire array on silicon for enhanced photoelectrochemical hydrogen production
}

\author{
Guancai Xie a,b,, , Saad Ullah Jan a,b,, , Zejian Dong a,b, Yawen Dai a,b, Rajender Boddula a, \\ Yuxuan Wei a,b, Chang Zhao a,b, Qi Xin a, Jiao-Na Wang c, Yinfang Du c, Lan Ma c, \\ Beidou Guo a,b,\#, Jian Ru Gong a,b,* \\ a Chinese Academy of Sciences (CAS) Center for Excellence in Nanoscience, CAS Key Laboratory of Nanosystem and Hierarchy Fabrication, National Center \\ for Nanoscience and Technology, Beijing 100190, China \\ b University of CAS, Beijing 100049, China \\ c Beijing Institute of Fashion Technology, Beijing 100029, China
}

\section{A R T I C L E I N F O}

Article history:

Received 21 June 2019

Accepted 18 July 2019

Published 5 January 2020

\section{Keywords:}

Core/shell nanowire

$\mathrm{GaP}$

GaPN

Hydrogen production

$\mathrm{Si}$

Solar water splitting

Tandem structure

\begin{abstract}
A B S T R A C T
Simultaneously improving the efficiency and stability on a large scale is significant for the development of photoelectrochemical (PEC) water splitting systems. Here, we demonstrated a novel design of GaP/GaPN core/shell nanowire (NW) decorated p-Si photocathode for improved PEC hydrogen production performance compared to that of bare p-Si photocathode. The formation of the p-n junction between p-Si and GaP NW promotes charge separation, and the lower conduction band position of GaPN relative to that of GaP further facilitates the transfer of photogenerated electrons to the electrode surface. In addition, the NW morphology both shortens the carrier collection distance and increases the specific surface area, which result in superior reaction kinetics. Moreover, introduction of $\mathrm{N}$ in GaP is beneficial for enhancing the light absorption as well as stability. Our efficient and facile strategy can be applied to other solar energy conversion systems as well.
\end{abstract}

(C) 2020, Dalian Institute of Chemical Physics, Chinese Academy of Sciences. Published by Elsevier B.V. All rights reserved.

Solar energy can be effectively utilized to alleviate the global energy and environmental crisis. Among the various solar energy harvesting technologies, hydrogen production through photoelectrochemical (PEC) water splitting is a promising way of realizing solar energy conversion and storage and remains the center of attraction for the scientific community [1-6]. One of the key requirements for the PEC system is an efficient and stable photocathode $[7,8]$. In the past few decades, researchers have been searching for better materials for PEC water splitting [5,9-13]. Si, an earth abundant and matured industrial material, has been widely used for the PEC hydrogen evolution reaction (HER) because of its bandgap $\left(E_{\mathrm{g}}=1.1 \mathrm{eV}\right)$, which matches well with the solar spectrum and is suitable for reducing water to produce hydrogen [14-19]. However, the sluggish surface reaction and instability in electrolytes limit its practical application in solar hydrogen production [4,20-23]. Tremendous

\footnotetext{
* Corresponding author. Tel: +86-10-82545649; Fax: +86-10-62656765; E-mail: gongjr@nanoctr.cn

\# Corresponding author. Tel: +86-10-82545649; Fax: +86-10-62656765; E-mail: guobd@nanoctr.cn

${ }^{\dagger}$ These authors contributed equally to this paper.

The authors acknowledge financial support for this work from the National Natural Science Foundation of China (21422303, 21573049, 21872043, 81602643), Beijing Natural Science Foundation (2142036), Youth Innovation Promotion Association, and Special Program of "One Belt One Road" of CAS.

DOI: S1872-2067(19)63465-0 | http://www.sciencedirect.com/science/journal/18722067 | Chin. J. Catal., Vol. 41, No. 1, January 2020
} 
efforts have been devoted to improving the Si performance by coating metals [24,25], despite the issue of parasitic light absorption [26]. Some oxide overlayers (such as $\mathrm{Fe}_{2} \mathrm{O}_{3}$ [22], $\mathrm{TiO}_{2}$ [27-29], and ZnO [30]) have been used to protect the Si photocathode, which compromises the maximum achievable photocurrent efficiency, and the poor HER catalytic performance of these oxide overlayers is often compensated by coupling with expensive electrocatalysts like $\mathrm{Pt}$ and $\mathrm{Ru}$ [26]. Additionally, associated problems such as low conductivity, poor chemical stability, and large lattice mismatch, which result in sluggish interfacial charge transfer and poor film quality, limit the PEC performance [30-32]. Therefore, a more efficient overlayer is urgently needed to obtain a high performance with Si photocathode.

III-V materials, which show excellent charge carrier transport properties, have been widely used in the optoelectronic field. Among them, GaP, which exhibits a direct bandgap of $2.78 \mathrm{eV}$ and an indirect bandgap of $2.26 \mathrm{eV}$ [33], satisfies the requirement of a large bandgap absorber that can produce an optimal tandem structure with $\mathrm{Si}$, which can serve as the lower bandgap material [34]. Owing to the existence of $P$ vacancies, the GaP nanowires (NWs) grown by chemical vapor deposition (CVD) method are inherently n-type [35,36]. Therefore, the growth of GaP on Si through CVD method will lead to the formation of a p-n junction between the p-Si and the n-GaP NWs that improves the efficiency of charge separation. Otherwise, the small lattice mismatch between $\mathrm{Si}$ and GaP (only 0.36\%) ensures that the high-quality $\mathrm{GaP}$ can grow epitaxially on the $\mathrm{Si}$ substrate, which results in a better passivation effect and more efficient charge transfer. Moreover, the fabrication of $\mathrm{GaP} / \mathrm{Si}$ heterojunction is a cost-effective strategy compared to the widely used expensive native substrate [37]. Considering the short minority carrier diffusion lengths $(\mathrm{Ld})$ of $\mathrm{GaP}$, which are small $(6 \mu \mathrm{m}-100 \mathrm{~nm})$ [34] relative to its absorption depths (500 $\mu \mathrm{m}$ near bandgap, $10 \mu \mathrm{m}$ at $486 \mathrm{~nm}$ ) [33,34], nanostructuring can facilitate the rapid diffusion of the photogenerated charge carriers [38]. In this context, one-dimensional (1D) NWs can afford a promising nanostructure. The highly anisotropic 1D geometry can decouple the long axis necessary for complete absorption of light from the orthogonal short axis, thereby allowing effective charge transport and collection over short distances [3]. However, the photodecomposition potentials of $\mathrm{GaP}$ are in-between the conduction and covalent band edge energy levels, therefore, this material usually undergoes degradation under operating conditions when employed as a photoelectrode $[20,33,37,39]$. Since it is known that GaP is more unstable than CdS, the protection layer is always directly added onto GaP for solar water splitting $[37,39,40]$. Furthermore, GaP exhibits poor light absorption, specifically in the long-wavelength range [33].

Here, we design a novel GaP/GaPN core/shell NW decorated $\mathrm{p}-\mathrm{Si}$ photocathode ( $\mathrm{p}-\mathrm{Si}$-cs-NW) for PEC hydrogen production that shows a greatly improved performance compared to that of the bare p-Si photocathode. GaPN displays a higher stability because of the existence of stronger ionic bonds, compared to $\mathrm{GaP}$ [41]. In addition, incorporation of a small amount (usually several percentages) of $\mathrm{N}$ atoms into the GaP host lattice not only significantly reduces the bandgap via the giant bowing effect but also transforms it from an indirect bandgap semiconductor (in the case of GaP) to a quasi-direct bandgap material (in the case of GaNP), which enhances the light absorption $[41,42]$. The alignment of energy levels at the p-Si-cs-NW interface will favor the charge transfer. In addition, the NW nanostructure $[3,31,38]$ can both shorten the carrier collection distance and increase the specific surface area, which promote the reaction kinetics and improve the anti-reflection property of the photoelectrode $[43,44]$. This efficient and scalable strategy is expected to yield higher PEC water-splitting performances.

The p-Si-cs-NW photocathode was fabricated by synthesizing $\mathrm{GaP} / \mathrm{GaPN}$ cs-NWs on a p-Si(100) substrate through the facile CVD method. After the GaP NW growth, the Au catalyst nanoparticles (NPs) were removed, which was followed by annealing of the as-grown NWs in $\mathrm{NH}_{3}$ atmosphere at $750{ }^{\circ} \mathrm{C}$ to form a GaPN shell as a protection layer (Scheme 1, Figs. S1-5).

Representative scanning electron microscope (SEM) images (Fig. 1(a) and 1(b)) show that the as-synthesized free-standing straight GaP NWs exhibit diameters that are nearly $100 \mathrm{~nm}$ and lengths of the order of several micrometers. The high-resolution transmission electron microscopy (HRTEM) image (Fig. 1(c)) of the NW with a lattice distance of $0.31 \mathrm{~nm}$ confirms that it is GaP [45]. The inset of the fast Fourier transform (FFT) image suggests that the GaP NW grows along the [111] direction and adopts the zinc-blende structure $[39,46]$. Energy-dispersive spectroscopy (EDS) mapping was utilized to analyze the elemental distribution in the catalyst NPs, and Ga, $\mathrm{P}$, and Au can be seen clearly on the top of each NW (Fig. 1(d)-(g)), which confirm that the NWs grow through the vapor liquid solid mechanism [47-49]. After removing the Au NPs and annealing in $\mathrm{NH}_{3}$, the morphology of the cs-NW displays negligible differences (Fig. 1(h)-(i)) when compared with that of GaP, whereas an amorphous shell with the thickness of $\sim 2.7$ nm was observed in the HRTEM image shown in Fig. 1(j). The thickness of the amorphous shell can be tuned by varying the annealing time (Fig. S6). The elemental maps of the cs-NW show concentration of $\mathrm{Ga}, \mathrm{P}$, and dilute $\mathrm{N}$, which is due to the presence of an extremely thin shell (Fig. 1(k)-(n)). The EDS line scan profile (in the radial direction of the NW) was also obtained to observe the distribution of $\mathrm{N}$; the very low $\mathrm{N}$ signal,

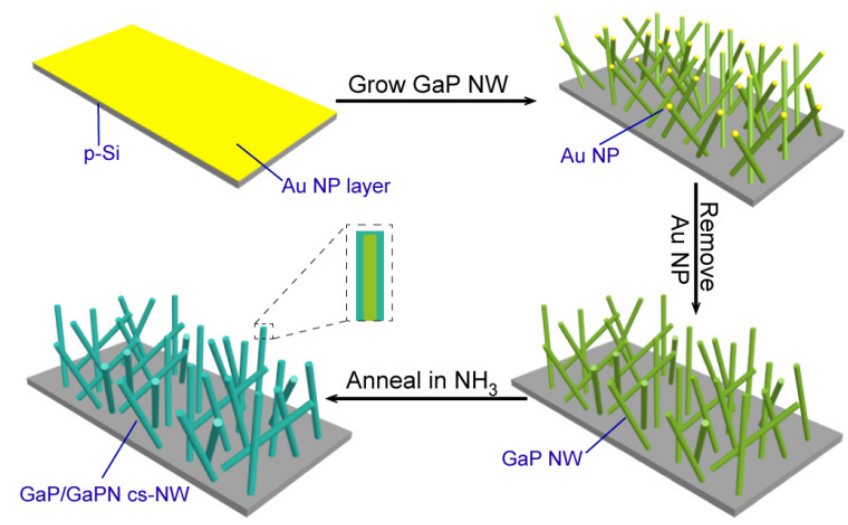

Scheme 1. Illustration of the fabrication of p-Si-cs-NW photocathode. The zoomed-in area shows the cross-section of GaP/GaPN cs-NW. 


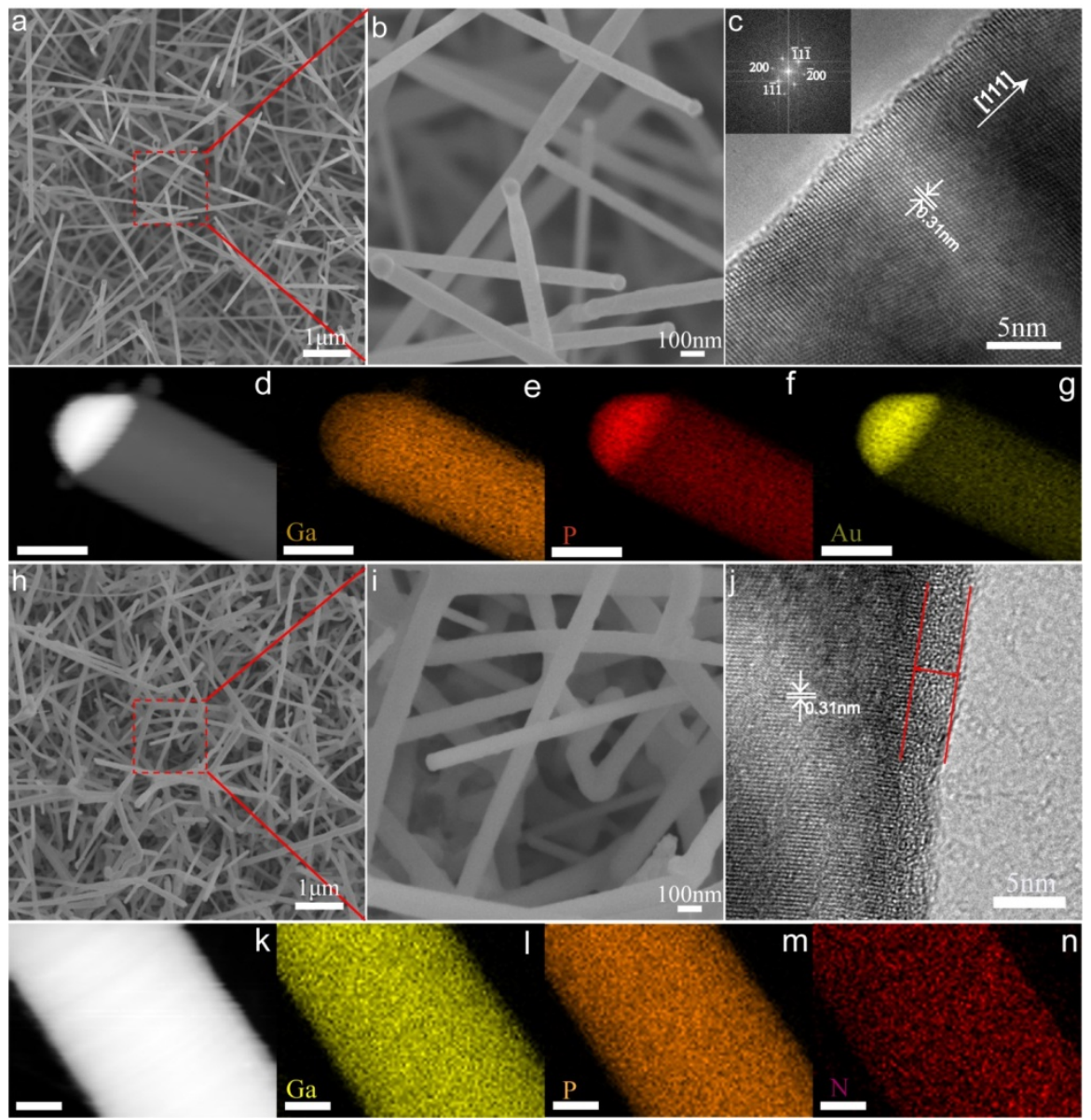

Fig. 1. Low-(a) and high-(b) magnification SEM images of GaP NWs. (c) HRTEM image of GaP NW, inset: FFT image of the GaP NW body. (d) High-angle annular dark field scanning transmission electron microscopy (HAADF-STEM) image of the GaP NWs (scale bars: $50 \mathrm{~nm}$ ). (e-g) TEM EDS mapping data of the GaP NWs (scale bars: $50 \mathrm{~nm}$ ). Low-(h) and high-(i) magnification SEM images of cs-NW. (j) HRTEM image of the cs-NW. (k) HAADF-STEM image of the cs-NW. (l-n) TEM EDS maps of the cs-NW (scale bars: $25 \mathrm{~nm}$ ).

compared to the signals of Ga and $\mathrm{P}$, further confirms the formation of the thin shell on the surface of the GaP NW (Fig. S7). The atomic ratio of $\mathrm{Ga} / \mathrm{P} / \mathrm{N}$ in the as-synthesized nanowires is 47.5:41.8:6.6 (Fig. S8).

To investigate the crystal structure and the effect of $\mathrm{N}$ doping on the as-grown GaP NWs, the X-ray diffraction (XRD) (Fig. 2(a)) patterns of p-Si-cs-NW were collected, along with that of the GaP NWs as a control sample, by using grazing incidence mode to avoid the effect of the reflections from the underlying
Si substrate [5]. Both the samples show sharp diffraction peaks that are associated with zinc-blende GaP (PDF card no. 32-0397), which suggest an excellent crystallinity [50]. A slight shift in the major peak position was observed after the $\mathrm{NH}_{3}$ annealing, which clarifies that $\mathrm{GaP}$ is the main component even after the incorporation of $\mathrm{N}$.

Raman spectroscopy (Fig. 2(b)) was performed to better understand the structural changes induced by $\mathrm{N}$ incorporation in p-Si-cs-NW. For a comparison, the p-Si-GaP NW sample was
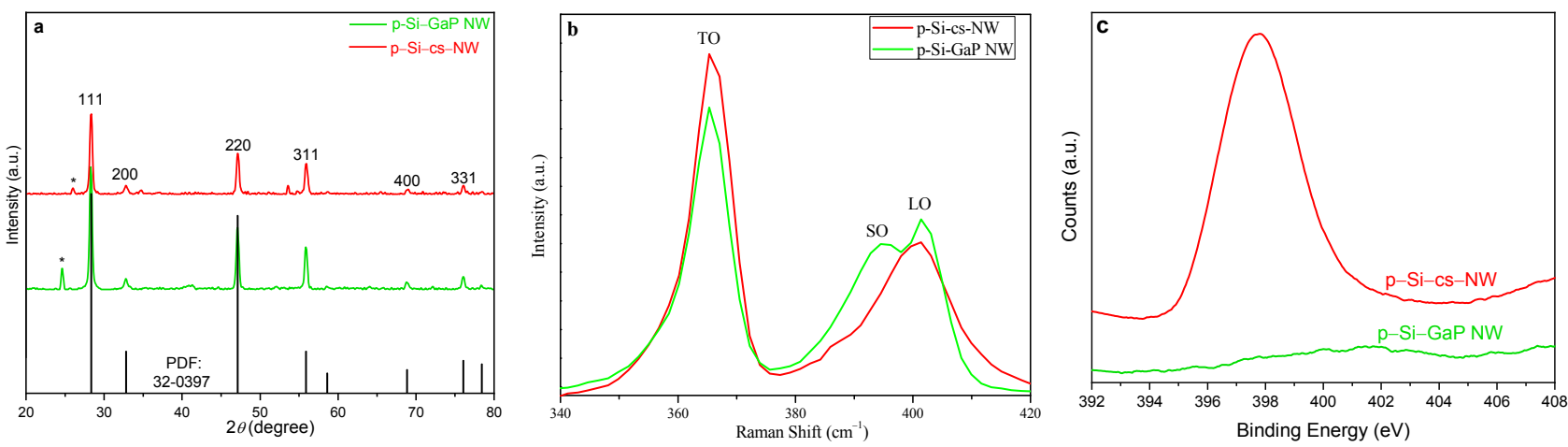

Fig. 2. XRD pattern (a), Raman spectra (b), and X-ray photoelectron spectroscopy (XPS) N 1s patterns (c) of p-Si-cs-NW and p-Si-GaP NW. 
also analyzed. For both the samples, two peaks at 365 and 401 $\mathrm{cm}^{-1}$ are observed that correspond to the transverse (TO) and longitudinal (LO) phonon modes of GaP, respectively [47]. The appearance of the surface optical (SO) peak for p-Si-cs-NW [51], which is located between 390 and $400 \mathrm{~cm}^{-1}$, is in accordance with the Raman results of the cs-NW reported previously, where the SO mode is a signature of the incorporation of $\mathrm{N}$ [52]. Its occurrence is usually interpreted by a break in the translational symmetry, which, in our case, can be caused by the insertion of N into the GaP matrix [48]. XPS was employed to examine the chemical environment [46] of the GaP NWs before and after the annealing in $\mathrm{NH}_{3}$. The $\mathrm{N} 1 s$ XPS peak at $\sim 397.5 \mathrm{eV}$ for the samples annealed in $\mathrm{NH}_{3}$ indicates that the $\mathrm{N}$ atom is bound to the Ga atom [46] (Fig. 2(c)), whereas the observance of no peaks at $400 \mathrm{eV}$ or higher binding energies suggests the absence of other $\mathrm{N}$ species $\left(\mathrm{N}_{2}\right.$ or $\mathrm{NO}_{x}$ groups) [46]. In summary, HRTEM, Raman, and XPS together prove that the thin GaPN shell developed on the surface of GaP NWs after annealing in $\mathrm{NH}_{3}$ forms the GaP/GaPN core-shell NW structure on the $\mathrm{p}$-Si substrate.

The photocurrent density-applied potential $(U-V)$ characteristics of the p-Si-cs-NW photocathode (Fig. 3(a)) were recorded under the irradiation of standard simulated AM 1.5G sunlight (100 $\mathrm{mW} \mathrm{cm}^{-2}$ ) to evaluate the PEC HER performance, along with that of $\mathrm{p}-\mathrm{Si}$ as a comparison. The dark responses of both the electrodes are very small compared to their corresponding photoresponses. The bare p-Si shows a large negative onset potential $(-0.77 \mathrm{~V}$, blue line $)$ and displays no photocurrent at the water reduction potential. In contrast, the p-Si-cs-NW photocathode reveals a larger photocurrent with a significant positive shift in the onset potential to $\sim 0.14 \mathrm{~V}$. The photocurrent density at the water reduction potential is $-0.3 \mathrm{~mA} \mathrm{~cm}^{-2}$ and the saturated photocurrent density reaches $-8.8 \mathrm{~mA} \mathrm{~cm}^{-2}$ at -0.76 $\mathrm{V}$. The incident photon-to-current conversion efficiency (IPCE) of p-Si-cs-NW (Fig. 3(b)) is lower than 15\% in the wavelength range below $450 \mathrm{~nm}$ and increases rapidly with increasing wavelength, reaching the highest value of $50 \%$ at $800 \mathrm{~nm}$. The PEC activity shows no obvious decrease over $10 \mathrm{~h}$, which confirms the dramatically improved stability, thanks to the protection of GaPN (Fig. S9).

To explore the fundamental reason behind the improve- ment in the performance of the p-Si-cs-NW photocathode compared to that of the bare $\mathrm{p}-\mathrm{Si}$, UV-vis absorption and electrochemical impedance spectroscopy (EIS) were employed to investigate the light absorption and charge transfer properties of the photocathodes. The absorption spectra (Fig. 4(a)) reveal that both p-Si-GaP NW and p-Si-cs-NW structures on the Si substrate increase the light absorption at wavelengths shorter than $\sim 500 \mathrm{~nm}$, and $\mathrm{N}$ doping increases the light absorption at longer wavelengths owing to the decrease in the bandgap and the formation of the quasi-direct bandgap material GaPN [41]. This tandem heterostructure ensures efficient light absorption over the entire wavelength range, which contributes to the activity enhancement. In addition, this heterostructure is beneficial to the charge transfer at the two interfaces. First, the p-n junction formed between $\mathrm{p}-\mathrm{Si}$ and GaP improves the charge separation and, second, the conduction band of the GaPN shell is slightly lower than that of the GaP core [53] (Fig. 4(b)). Consequently, the photogenerated electrons prefer to move from $\mathrm{Si}$ and GaP to GaPN, while holes migrate in the reverse direction, which increases the charge separation efficiency. Furthermore, owing to the nanostructure morphology, both the shortened carrier collection distance and the significantly increased specific surface area $[3,31,38,44]$ of the $\mathrm{p}$-Si-cs-NW photocathode promote the reaction kinetics in the form of a smaller overpotential, compared to that of the planar $\mathrm{p}$-Si. As evidenced from the EIS data (Fig. 4(c) and 4(d)), the diameter of the p-Si-cs-NW semicircle is very small compared to that of p-Si semicircle, which is indicative of a smaller charge transfer resistance at the electrode/electrolyte interface, which further confirms the occurrence of faster charge transfer at the interface of p-Si-cs-NW.

In summary, we demonstrated the design of p-Si-cs-NW decorated p-Si photocathode for improved PEC hydrogen production performance compared to that of bare $\mathrm{p}$-Si. The formation of the p-n junction between $\mathrm{p}-\mathrm{Si}$ and GaP NW favors charge separation, and the lower conduction band position of GaPN relative to that of GaP further facilitates the transfer of photogenerated electrons to the electrode surface. In addition, the NW morphology both shortens the carrier collection distance and increases the specific surface area, which promote the reaction kinetics. Moreover, the introduction of $\mathrm{N}$ in GaP is
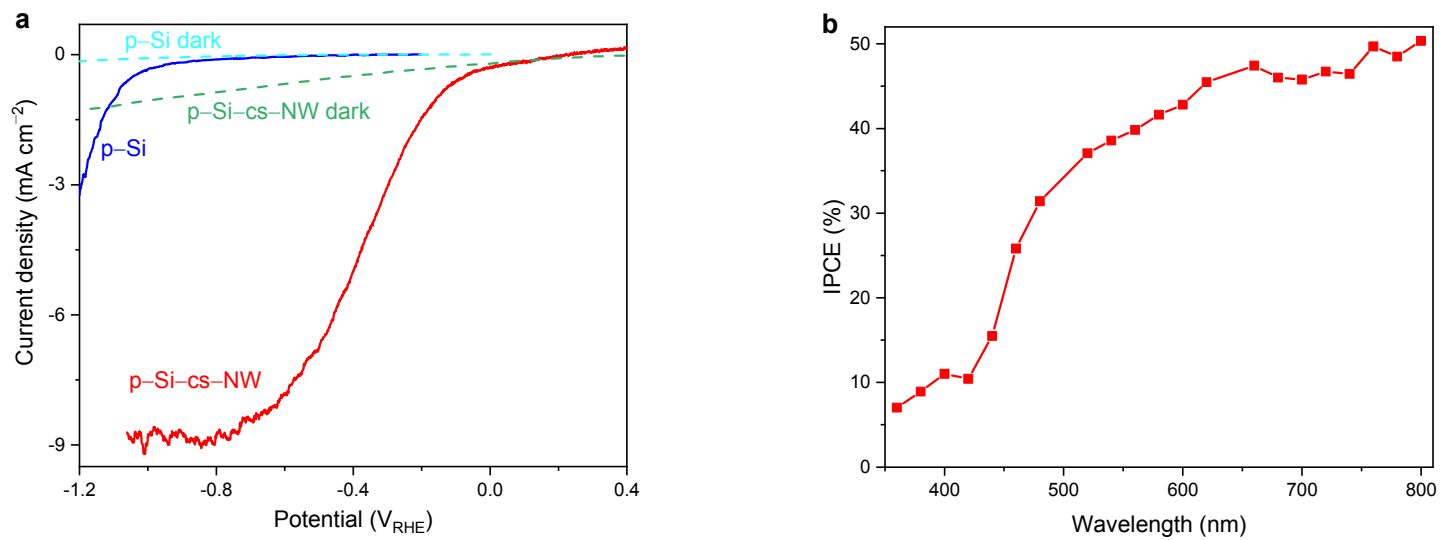

Fig. 3. (a) J-V curves of p-Si and p-Si-cs-NW photocathodes. (b) Result of IPCE test performed on the p-Si-cs-NW photocathode. 

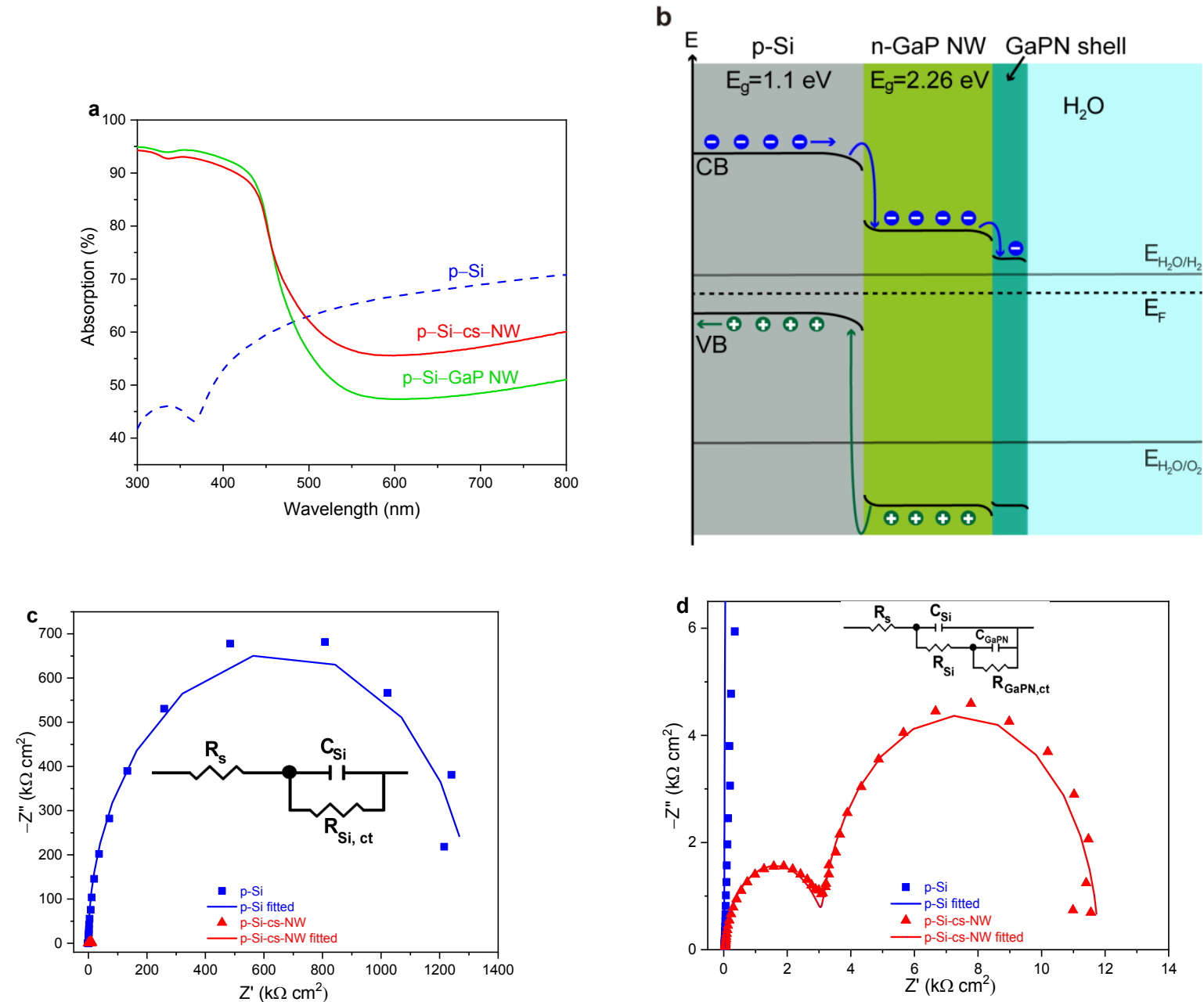

Fig. 4. (a) UV-vis absorption spectra of p-Si, p-Si-GaP NW, and p-Si-cs-NW. (b) Energy band scheme of p-Si-cs-NW photocathode. Nyquist curves (c) and enlarge views (d) of the EIS plots for p-Si and p-Si-cs-NW photocathodes. In the equivalent circuits, $\mathrm{R}_{\mathrm{s}}, \mathrm{R}_{\mathrm{si}, \mathrm{ct}}, \mathrm{R}_{\mathrm{si}}$, and $\mathrm{R}_{\mathrm{GaPN}, \mathrm{ct}}$ represent the solution resistance and the charge transfer resistances at the Si-electrolyte interface, Si-GaPN interface, and GaPN-electrolyte interface, respectively. $\mathrm{C}_{\mathrm{Si}}$ and $\mathrm{C}_{\mathrm{GaPN}}$, represent the capacitances of the space charge regions in Si and GaPN, respectively.

beneficial for enhancing the light absorption, as well as for improving the stability. Further improvement in the PEC performance is expected by optimizing the structural parameters and loading suitable electrocatalysts into this structure. Our efficient and facile strategy can also be applied to other solar energy conversion systems.

\section{Supporting Information}

p-Si-GaP NW, p-Si-cs-NW growth experimental details, AFM, SEM, EDX, XRD patterns, stability test, fabrication of photoelectrode, electrochemical measurements, characterizations details of samples.

\section{References}

[1] K. Sivula, R. van de Krol, Nat. Rev. Mater., 2016, 1, 15010.

[2] Y. Lv, A. Batool, Y. Wei, Q. Xin, R. Boddula, S. U. Jan, M. Z. Akram, L. Tian, B. Guo, J. R. Gong, ChemElectroChem, 2019, 6, 2497-2502.

[3] B. Guo, L. Tian, W. Xie, A. Batool, G. Xie, Q. Xiang, S. U. Jan, R. Bod- dula, J. R. Gong, Nano Lett., 2018, 18, 5954-5960.

[4] B. Guo, A. Batool, G. Xie, R. Boddula, L. Tian, S. U. Jan, J. R. Gong, Nano Lett., 2018, 18, 1516-1521.

[5] K. Zhang, T. Dong, G. Xie, L. Guan, B. Guo, Q. Xiang, Y. Dai, L. Tian, A. Batool, S. U. Jan, R. Boddula, A. A. Thebo, J. R. Gong, ACS Appl. Mater. Interfaces, 2017, 9, 42723-42733.

[6] P. Kuang, L. Zhang, B. Cheng, J. Yu, Appl. Catal. B, 2017, 218, 570-580.

[7] S. Vanka, E. Arca, S. Cheng, K. Sun, G. A. Botton, G. Teeter, Z. Mi, Nano Lett., 2018, 18, 6530-6537.

[8] Z. Wang, L. Wang, Chin. J. Catal., 2018, 39, 369-378.

[9] I. S. Cho, H. S. Han, M. Logar, J. Park, X. Zheng, Adv. Energy Mater., 2016, 6, 1501840.

[10] N. Kornienko, N. A. Gibson, H. Zhang, S. W. Eaton, Y. Yu, S. Aloni, S. R. Leone, P. Yang, ACS Nano, 2016, 10, 5525-5535.

[11] Y. Li, T. Takata, D. Cha, K. Takanabe, T. Minegishi, J. Kubota, K. Domen, Adv Mater., 2013, 25, 125-131.

[12] M. Zhong, Y. Ma, P. Oleynikov, K. Domen, J.-J. Delaunay, Energy Environ. Sci., 2014, 7, 1693-1699.

[13] Y. Wang, Y. Li, S. Cao, J. Yu, Chin. J. Catal., 2019, 40, 867-874.

[14] Q. Ding, F. Meng, C. R. English, M. Caban-Acevedo, M. J. Shearer, D. Liang, A. S. Daniel, R. J. Hamers, S. Jin, J. Am. Chem. Soc., 2014, 136, 


\section{Graphical Abstract}

Chin. J. Catal., 2020, 41: 2-8 doi: S1872-2067(19)63465-0

\section{GaP/GaPN core/shell nanowire array on silicon for enhanced photoelectrochemical hydrogen production}

Guancai Xie, Saad Ullah Jan, Zejian Dong, Yawen Dai, Rajender Boddula, Yuxuan Wei, Chang Zhao, Qi Xin, Jiao-Na Wang, Yinfang Du, Lan Ma, Beidou Guo*, Jian Ru Gong*

National Center for Nanoscience and Technology; University of Chinese Academy of Sciences; Beijing Institute of Fashion Technology
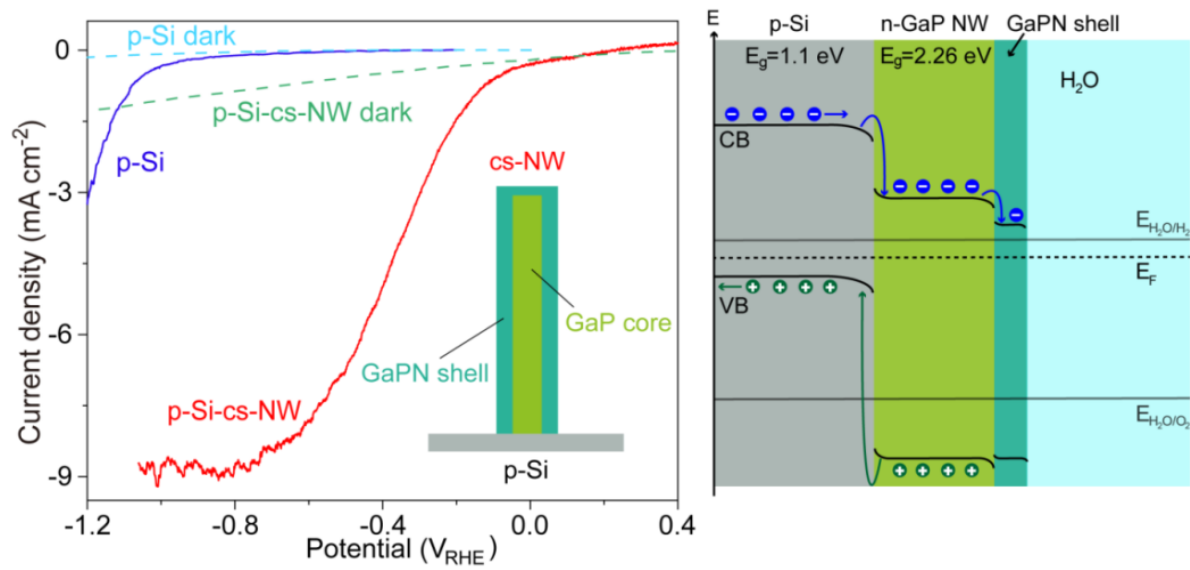

p-Si-GaP/GaPN core/shell heterostructure demonstrates improved PEC HER performance owing to enhanced charge separation and increased light absorption, which result from the novel structural design.

8504-8507.

[15] M. Basu, Z. W. Zhang, C. J. Chen, P. T. Chen, K. C. Yang, C. G. Ma, C. C. Lin, S. F. Hu, R. S. Liu, Angew. Chem. Int. Ed., 2015, 54, 6211-6216.

[16] L. Wang, X. Gu, Y. Zhao, M. Wei, C. Huang, Y. Qiang, Appl. Surf. Sci., 2018, 448, 126-132.

[17] H. Meng, K. Fan, J. Low, J. Yu, Dalton Trans., 2016, 45, 13717-13725.

[18] R. Fan, G. Huang, Y. Wang, Z. Mi, M. Shen, Appl. Catal. B, 2018, 237, 158-165.

[19] W. Zhou, F. Niu, S. S. Mao, S. Shen, Appl. Catal. B, 2018, 220, 362-366.

[20] M. G. Walter, E. L. Warren, J. R. Mckone, S. W. Boettcher, Q. Mi, E. A. Santori, N. S. Lewis, Chem. Rev., 2010, 110, 6446-6473.

[21] J. Zhao, L. Cai, H. Li, X. Shi, X. Zheng, ACS Energy Lett., 2017, 2, 1939-1946.

[22] A. Kargar, S. J. Kim, P. Allameh, C. Choi, N. Park, H. Jeong, Y. Pak, G. Y. Jung, X. Pan, D. Wang, S. Jin, Adv. Funct. Mater., 2015, 25, 2609-2615.

[23] J. Feng, M. Gong, M. J. Kenney, J. Z. Wu, B. Zhang, Y. Li, H. Dai, Nano Res., 2015, 8, 1577-1583.

[24] R. N. Dominey, N. S. Lewis, J. A. Bruce, D. C. Bookbinder, M. S. Wrighton, J. Am. Chem. Soc., 1982, 104, 467-482.

[25] E. L. Warren, J. R. McKone, H. A. Atwater, H. B. Gray, N. S. Lewis, Energy Environ. Sci., 2012, 5, 9653-9661.

[26] D. Bae, B. Seger, P. C. K. Vesborg, O. Hansen, I. Chorkendorff, Chem. Soc. Rev., 2017, 46, 1933-1954.

[27] S. Li, P. Zhang, X. Song, L. Gao, ACS Appl. Mater. Interfaces, 2015, 7, 18560-18565.

[28] X. Zhu, Z. Guan, P. Wang, Q. Zhang, Y. Dai, B. Huang, Chin. J. Catal., 2018, 39, 1704-1710.

[29] Z. Dong, D. Ding, T. Li, C. Ning, Appl. Surf. Sci., 2018, 436, 125-133.

[30] Z. Bao, X. Xu, G. Zhou, J. Hu, Nanotechnology, 2016, 27, 305403.
[31] K. Sun, S. Shen, Y. Liang, P. E. Burrows, S. S. Mao, D. Wang, Chem. Rev., 2014, 114, 8662-8719.

[32] A. Kargar, K. Sun, Y. Jing, C. Choi, H. Jeong, G. Y. Jung, S. Jin, D. Wang, ACS Nano, 2013, 7, 9407-9415.

[33] M. Malizia, B. Seger, I. Chorkendorff, P. C. K. Vesborg, J. Mater. Chem. A, 2014, 2, 6847-6853.

[34] N. C. Strandwitz, D. B. Turner-Evans, A. C. Tamboli, C. T. Chen, H. A. Atwater, N. S. Lewis, Adv. Energy Mater., 2012, 2, 1109-1116.

[35] R. Krauserehberg, A. Polity, W. Siegel, G. Kuhnel, Semicond. Sci. Technol., 1993, 8, 290.

[36] S. Lee, W. Wen, Q. Cheek, S. Maldonado, J. Cryst. Growth, 2018, 482, 36-43.

[37] M. Alqahtani, S. Sathasivam, F. Cui, L. Steier, X. Xia, C. Blackman, E. Kim, H. Shin, M. Benamara, Y. I. Mazur, G. J. Salamo, I. P. Parkin, H. Liu, J. Wu, J. Mater. Chem. A., 2019, 7, 8550-8558.

[38] Y. Abbas, Z. Zuhra, N. Akhtar, S. Ali, J.R. Gong, ACS Appl. Energy Mater., 2018, 1, 3529-3536.

[39] A. Standing, S. Assali, L. Gao, M. A. Verheijen, D. van Dam, Y. Cui, P. H. Notten, J. E. Haverkort, E. P. A. M. Bakkers, Nat Commun., 2015, 6, 7824.

[40] J. Li, N. Wu, Catal. Sci. Technol., 2015, 5, 1360-1384.

[41] T. G. Deutsch, C. A. Koval, J. A. Turner, J. Phys. Chem. B, 2006, 110, 25297-25307.

[42] S. L. Chen, W. M. M. Chen, I. A. Buyanova, J. Phys. Chem. C, 2018, 122, 19212-19218.

[43] H. K. Kang, J. Y. Kim, M. S. Noh, C. Y. Kang, Y. D. Kim, M. H. Cho, J. D. Song, Nano Energy, 2018, 53, 57-65.

[44] S. Liu, Z. R. Tang, Y. Sun, J. C. Colmenares, Y. J. Xu, Chem. Soc. Rev., 2015, 44, 5053-5075.

[45] A. Kargar, S. Sukrittanon, C. Zhou, Y. G. Ro, X. Pan, S. A. Dayeh, C. W. Tu, S. Jin, Small, 2017, 13, 1603574.

[46] W. Wen, A. I. Carim, S. M. Collins, M. J. Price, S. L. Peczonczyk, S. 
Maldonado, J. Phys. Chem. C, 2011, 115, 22652-22661.

[47] Q. Xiong, R. Gupta, K. W. Adu, E. C. Dickey, G. D. Lian, D. Tham, J. E. Fischer, P. C. Eklunda, J. Nanosci. Nanotechnol., 2003, 3, 335-339.

[48] M. Steidl, K. Schwarzburg, B. Galiana, T. Kups, O. Supplie, P. Kleinschmidt, G. Lilienkamp, T. Hannappel, Nanotechnology, 2019, 30, 104002.

[49] M. Steidl, M. Wu, K. Peh, P. Kleinschmidt, E. Spiecker, T. Hannappel, Nanoscale Res. Lett., 2018, 13, 417.

[50] H. W. Seo, S. Y. Bae, J. Park, M.-I. Kang, S. Kim, Chem. Phys. Lett.,
2003, 378, 420-424.

[51] A. Dobrovolsky, S. Sukrittanon, Y. J. Kuang, C. W. Tu, W. M. Chen, I. A. Buyanova, Appl. Phys. Lett., 2014, 105.

[52] A. Dobrovolsky, S. Sukrittanon, Y. Kuang, C. W. Tu, W. M. Chen, I. A. Buyanova, Small, 2014, 10, 4403-4408.

[53] W. Walukiewicz, W. Shan, J. W. Ager III, D. R. Chamberlin, E. E. Haller, J. F. Geisz, D. J. Friedman, J. M. Olson, S. R. Kurtz, Electrochem. Soc. Proceedings Vol. 99-11, Seattle, WA, USA, 1999, 190-199.

\title{
$\mathrm{GaP} / \mathrm{GaPN}$ 核壳纳米线阵列修饰的硅光阴极的光电化学制氢反应
}

\author{
谢关才 ${ }^{\mathrm{a}, \mathrm{b}, \dagger}$, Saad Ullah Jan ${ }^{\mathrm{a}, \mathrm{b}, \dagger}$ ，董泽健 ${ }^{\mathrm{a}, \mathrm{b}}$ ，代亚雯 ${ }^{\mathrm{a}, \mathrm{b}}$, Rajender Boddula ${ }^{\mathrm{a}}$ ，魏玉轩 ${ }^{\mathrm{a}, \mathrm{b}}$ ，赵 唱 ${ }^{\mathrm{a}, \mathrm{b}}$,

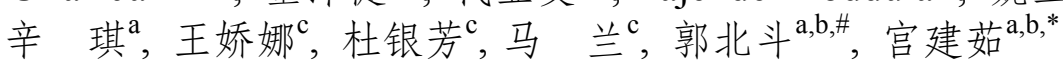 \\ a国家纳米科学中心, 中科院纳米系统与多级次重点实验室, 中科院纳米科学卓越创新中心, 北京 100190 \\ $\mathrm{b}$ 中国科学院大学, 北京 100049 \\ c 北京服装学院, 北京100029
}

\begin{abstract}
摘要: 能够大规模同时提升电极的催化效率和稳定性对光电化学分解水系统的开发具有重要意义. 硅是一种地球储量丰 富且成熟的工业材料, 由于其合适的带隙 $(1.1 \mathrm{eV})$ 和优异的导电性, 已被广泛用于光电化学制氢反应. 然而, 缓慢的表面催 化反应和在电解液中的不稳定性限制了其在太阳能制氢中的实际应用. III-IV族半导体材料也具有较高的载流子传输特 性且被广泛用于光电器件. 其中, $\mathrm{GaP}$ 的直接带隙和间接带隙分别为 2.78 和 $2.26 \mathrm{eV}$, 可与硅组成串联型光电极用于光电化 学分解水. 然而, $\mathrm{GaP}$ 的光腐蚀电位位于禁带中, 很容易在光电催化过程中发生光腐蚀而导致性能大幅下降. 本文报道了一 种新型的 $\mathrm{GaP} / \mathrm{GaPN}$ 核/壳纳米线修饰的p型硅(p-Si)串联型光阴极, 同未修饰的p-Si相比, 其光电化学制氢性能更高. 这可归 因于以下几点: (1) p-Si和 GaP纳米线之间形成的p-n结促进了电荷分离; (2) GaPN相对于 GaP具有更低的导带边位置, 进一 步促进了光生电子向电极表面的转移; (3)纳米线结构既缩短了光生载流子的收集距离, 又增加了比表面积, 从而加快了表 面反应动力学. 此外, 在 $\mathrm{GaP}$ 中引入氮元素还提高了体系的光吸收和稳定性. 我们所提出的高效、简便的改进策略可应用于 其他的太阳能转换体系.

利用简单的化学气相沉积法制备 $\mathrm{GaP} / \mathrm{GaPN}$ 核/壳纳米线修饰的p-Si光阴极. 首先在p-Si祄底上利用 $\mathrm{Au}$ 纳米颗粒作为催 化剂生长 $\mathrm{GaP}$ 纳米线; 然后, 去除 $\mathrm{Au}$ 催化剂, 并在氨气中退火便形成了 $\mathrm{GaP} / \mathrm{GaPN}$ 核壳纳米线. 高分辨透射电子显微镜, 拉 曼光谱和X射线光电子谱的表征结果均证实了氨气退火使得 $\mathrm{GaP}$ 纳米线表面形成了 $\mathrm{GaPN}$ 的薄壳层, 同时证明了 $\mathrm{GaP} / \mathrm{GaPN}$ 核壳纳米线具有可调的核壳结构. 在模拟太阳光下作为光阴极用于光解水制氢反应时, GaP/GaPN核壳纳米线修饰的p-Si 光阴极的起始电位为 $\sim 0.14 \mathrm{~V}$, 而未修饰的p-Si电极的起始电位大约在 $-0.77 \mathrm{~V}$. 而且, $\mathrm{GaP} / \mathrm{GaPN}$ 核/壳纳米线修饰的p-Si光 阴极比未修饰的p-Si光阴极具有更高的光电流密度, 在水的还原电位下, 其光电流密度为 $-0.3 \mathrm{~mA} \mathrm{~cm}$, 且饱和光电流密度 在 $-0.76 \mathrm{~V}$ 时达到了 $-8.8 \mathrm{~mA} \mathrm{~cm}$. 此外, $\mathrm{GaP} / \mathrm{GaPN}$ 核/壳纳米线修饰的p-Si光阴极的光电化学活性在 $10 \mathrm{~h}$ 内没有发生明显 下降. 由此可见 $\mathrm{GaP} / \mathrm{GaPN}$ 核/壳纳米线可以规模化有效地提升 $\mathrm{Si}$ 光电极的催化效率和稳定性.
\end{abstract}

关键词: 核壳纳米线; $\mathrm{GaP} ; \mathrm{GaPN}$; 制氢; 硅; 光解水; 串联结构

收稿日期: 2019-06-21. 接受日期: 2019-07-18. 出版日期: 2020-01-05.

*通讯联系人. 电话: (010)82545649; 传真: (010)62656765; 电子信箱: gongjr@nanoctr.cn

\#通讯联系人. 电话: (010)82545649; 传真: (010)62656765; 电子信箱: guobd@nanoctr.cn

†共同第一作者.

基金来源：国家自然科学基金(21422303, 21573049, 21872043, 81602643); 北京自然科学基金(2142036); 中国科学院青年创新促 进会; 中国科学院“一带一路”专项.

本文的电子版全文由Elsevier出版社在ScienceDirect上出版(http://www.sciencedirect.com/science/journal/18722067). 